Manuscript version. Final version appeared in Metascience 19(2): 285-288

(2010) and available at http://dx.doi.org/10.1007/s11016-010-9388-1

\title{
Novel approaches to models
}

\author{
Review of Mauricio Suárez (ed.) Fictions in Science: Philosophical \\ Essays on Modeling and Idealization. New York: Routledge. 2009. Pp \\ vii +282 . US \$118 HB.
}

\author{
Adam Toon \\ Department of Philosophy \\ University of Bielefeld \\ P.O. Box 100131 \\ 33501 Bielefeld, Germany \\ adam.toon@uni-bielefeld.de
}

Recent philosophy of science has seen a growing body of work that, in one way or another, seeks to relate scientific models to fiction. This stimulating volume brings together 13 papers that each reveal different ways in which the slogan that models are fictions may be spelled out, qualified, or resisted.

The volume takes its lead from Hans Vaihinger's Philosophy of "As If” (1911) and, in particular, from Arthur Fine's recent revival of Vaihinger's work. Fine's 1993 article, 'Fictionalism', is reprinted as the book's first chapter and provides an excellent introduction to Vaihinger's view. Vaihinger offers his own definition of fiction: unlike hypotheses, which are subject to verification, fictions 'contradict' reality and are known to do so. Despite this, some fictions may be 'virtuous', since they fulfill a useful function. Vaihinger saw fictions at work in many areas of human inquiry. For Fine, Vaihinger's ideas have particular resonance 
when it comes to scientific modelling:

Preeminently, the industry devoted to modeling natural phenomena, in every area of science, involves fictions in Vaihinger's sense. If you want to see what treating something "as if" it were something else amounts to, just look at most of what any scientist does in any hour of any working day. (pp. 34-35)

Vaihinger distinguished between genuine and semi-fictions: while both contradict reality, genuine fictions also involve internal contradictions. Mauricio Suárez’s own paper offers some contemporary examples. Current models of stellar structure invoke many assumptions that are known to be false (that the star is an isolated system, for example) and are therefore semi-fictions. The model of measurement in quantum theory, Suárez argues, is internally inconsistent, and thus a genuine fiction.

Aside from Fine and Suárez, however, few contributors to the volume make extensive use of Vaihinger's work. Although Alisa Bokulich identifies classical electron orbits in semiclassical mechanics as fictions in Vaihinger's sense, she finds his framework unable to draw important distinctions among the great variety of 'misrepresentations' in science, from phlogiston to frictionless planes. In particular, Bokulich argues, contra Vaihinger, that fictions may legitimately be used to explain, and that we must distinguish between explanatory fictions (like classical electron orbits) and non-explanatory ones, which may be "mere calculational tools" (p. 107).

Rather than looking to build upon Vaihinger's framework, most contributors to the volume (implicitly or explicitly) operate with a different notion of fiction. This is the everyday notion used to divide up bookstores and libraries. While it seems uncontroversial that models involve (at least semi-) fictions in Vaihinger's sense, whether they may be shelved along with novels, plays or films is another question. 
One of the most revealing discussions of the relationship between models and fiction is offered by Eric Winsberg. Winsberg notes that Vaihinger's definition, which makes “any representation that contradicts reality a fiction" (p. 179), doesn't correspond to our ordinary use of the term: a rough map is not fiction. Winsberg proposes an alternative definition: nonfiction is offered as a "good enough" guide to some part of the world (p. 181); fiction is not. An objection immediately suggests itself: surely some works of fiction are offered as guides to the world. Winsberg responds to this objection by considering the fable of the grasshopper and the ant. While the grasshopper sings and dances all summer, the ant collects food, and when winter comes the grasshopper must beg for charity. Although it offers lessons about how the world is, the fable is still fiction, Winsberg argues, because it is "a useful guide to the way the world is in some general sense" and not to its "prima facie representational target", a singing grasshopper and toiling ant. Nonfictions, by contrast, "point to a certain part of the world" and are a guide to that part of the world (p. 181, emphasis in original).

Thus, Winsberg thinks that it is wrong to characterise entire models, or the idealisations or abstractions they employ, as fiction simply because they are inexact. He does allow that there are some fictional elements in models, however. For example, nanomechanics models fractures in silicon by describing the point of fracture using quantum mechanics and the region immediately surrounding it using classical molecular dynamics. To bring together the descriptions of the two regions, the boundary between them is treated as if it contained 'silogen' atoms, which have some properties of silicon and some of hydrogen. Silogen atoms are fictions, Winsberg argues, since they are not offered as even a 'good enough' description of the atoms at the boundary; instead, they are used so that the overall model will work. This overall model, however, is nonfiction.

Winsberg's distinction is helpful, although I'm not sure whether it captures the difference between fiction and nonfiction. In particular, it seems to me that not all fiction that teaches us about the world does so in the way that Winsberg suggests. For example, historical novels 
like I, Claudius or biographical novels like Schindler's Ark arguably represent actual people, places and events. Moreover, given that they are historical or biographical novels (rather than, say, fantasy) they are offered as 'good enough' guides to those people, places and events in certain respects and we are entitled to take them as such. (Of course, they may also be inaccurate in some respects, but then so is nonfiction.)

Interestingly, looking to other papers in the volume suggests that entire models (and not just parts of them, like silogen atoms) may qualify as fiction on Winsberg's criteria. Like fables, such models are not offered as guides to some particular part of the world but instead give insight in a more indirect way. For example, Margaret Morrison provides an in-depth analysis of Maxwell's mechanical model of the ether. Maxwell's model is 'fictional', for Morrison, since it is "deliberately intended as [an] imaginary account whose physical similarity to the target system is not immediately obvious" (p. 112). Tarja Knuuttila even claims that it is typical of models that they are not offered as representations of some real system "at the very outset” (p. 219, emphasis in original). Drawing on recent characterisations of modelling by Peter Godfrey-Smith and Michael Weisberg, Knuuttila argues instead that models are "independent objects that are often investigated in their own right" and which bear some "looser" relationship to the world (p. 228).

Of course, it is one thing to draw a comparison between models and works of fiction; it is another to show that this comparison can be used to tell us anything interesting about scientific models. Thus, although Ronald Giere admits that Maxwell's ether model may be fiction, he doubts whether this tell us anything about the model's function. Like Morrison, Giere thinks that understanding how such models give us knowledge of the world will require a case-by-case analysis.

Some papers in the volume do attempt to use the comparison with fiction to give some general insights into scientific models, however. Particularly interesting is Catherine Elgin's 
account of the way models yield understanding. Elgin argues that models represent their targets by 'exemplifying' certain properties and "imputing" those properties to the target ( $\mathrm{p}$. 85). An object exemplifies a property if it instantiates that property and "points up, highlights, displays, or conveys" it (p. 81). Thus, sample cards for paint exemplify the color of the paint while merely instantiating many other properties (size, shape, etc.). Elgin argues that fictions may also exemplify certain properties and, in doing so, can aid our understanding. By focusing on "three or four families in a country village" and ignoring "confounding features" like the Napoleonic wars, Pride and Prejudice is able to exemplify certain features of social and moral life (pp. 82-83). Similarly with the ideal gas model, Elgin claims, "the behavior exemplified by ideal gas molecules in the model may enable us to recognise such behavior amid the confounding factors that ordinarily obscure what is going on in actual gases" (p. 84).

In his introduction, Suárez notes that the volume emphasises "practice ahead of ontology" (p. 11). In this respect, it differs from a lot of other recent work relating models and fiction. Although models often make assumptions that are satisfied by no actual, concrete objects, scientists talk as if there were such objects. This has led some to compare the ontology of models to that of fictional entities, like unicorns or Madame Bovary. Of course, this comparison quickly leads to deep waters: Do such objects exist? If they do, what are they? If they do not, how can we analyse our talk about them? An approach emphasising practice is therefore helpful.

On occasion, however, it seems that answers to ontological puzzles concerning models and fiction are presupposed, rather that legitimately deferred (on this point, see Thomson-Jones, M. 'Missing Systems and the Face Value Practice', Synthese, 2010). For example, Giere grants that models and fiction are ontologically "on a par" (p. 249) while arguing that philosophers of science need not say much more about the matter. And yet according to his own account of the activity of modelling, scientists use models to represent by describing 
their similarities to real systems in properties such as mass or velocity. This makes it hard to see how Giere can avoid entering into debates over fictional entities. After all, according to anti-realists there simply are no fictional entities and so (if the two really are 'on a par') there are no models. Claims concerning the similarity of models to the world would therefore have to be radically reinterpreted, along with our account of how models represent (for an attempt to do this, see Toon, A. 'The ontology of theoretical modelling: models as make-believe', Synthese, 2010).

Concerns over ontology aside, however, this volume offers a number of thought-provoking approaches to scientific models. The revival of Vaihinger's work is welcome, even if few contributors take up his ideas in detail. And the reader will find plenty of valuable insights into the relationship between models and fiction, and the way that reflecting on fiction might help us to understand scientific models. 